\title{
Residents's Subjective Assessment of Walkability Attributes in Objectively Assessed Neighbourhoods
}

\author{
SABEEN QURESHI*, JAVERIA MANZOOR SHAIKH**, AND SHEERAZ AHMED MEMON*** \\ RECEIVED ON 28.12.2017 ACCEPTED ON 12.02.2018
}

\begin{abstract}
The attributes of the built environment may influence walking in neighbourhood. The objective of this study is to find the association between objectively assessed and perceived built environment attributes. To achieve the objective of the study three neighbourhood of Putrajaya, Malaysia Precinct 8, 9 and 18 were selected. This study used NEWS (Neighbourhood Environment Walkability Scale) abbreviated version for the comparison of the residents' perceptions regarding attributes of three neighbourhoods of Putrajaya in Malaysia that differ on objective measures derived from a GIS (Geographical Information System) data basis and Putrajaya master plan. High-walkable neighbourhood residents reported built environment attributes ratings persistently higher as compared to the residents of the moderate and lowwalkable neighbourhood. Results from the high walkable neighborhood shows that on a 5-point Likert scale most residents perceived high ratings of within the range of "3" except for residential density as there is a different scoring procedure for it. There are lowest ratings perceived within the range of " 1 " for the attribute crime and according to the scoring procedure for crime lowest score reflects the highest level of walking.There is no significant difference found in the ratings for traffic hazards. Subjective measures of built environment attributes had moderate to high alpha $(\alpha)$ value. Hence theneighbourhood environment walkability scale can be used for subjective assessment in the tropical context.
\end{abstract}

Key Words: Built Environment, Geographical Information System, Walking, Environmental Perceptions.

\section{INTRODUCTION}

The importance of the influence of the built environment attributes on walking is creating more and more interest with the passage of time among the researchers [1-3]. Several studies showed that people who live near to destinations such as parks or commercial areas have easy access to them and is therefore the main factor that mainly encourage either one prefer to drive the automobile or choose to walk also their findings conclude that both objective and subjective measures of built environmental attributes are linked with walking [4-6]. Walking is the primary form of transportation in a neighbourhood due

Authors E-Mail: (sabeen.qureshi@faculty.muet.edu.pk, chairman.fabe@nhu.edu.pk, sheerazahmed.memon@faculty.muet.edu.pk) Department of Architecture, Mehran University of Engineering \& Technology, Jamshoro.

* $\quad$ Department of Architecture \&Built Environment, Nazeer Hussain University, Karachi.

*** Institute of Environmental Engineering \& Management, Mehran University of Engineering \& Technology, Jamshoro.

This is an open access article published by Mehran University Research Journal of Engineering and Technology, Jamshoro under the CC by 4.0 International License. 
to that, it has been a focus of considerable research.

Neighbourhood's built environment attributes may encourage walking for the various reasons like walking for transport, leisure or exercise. The subjective assessment of neighbourhood built environment attributes influencing walkability has been done by several methods yet there is limited study found on how these subjective assessments could have been related to corresponding attributes assessment based on objectives measures [7].

During the last few decades the two planning groups actively conducting research on walking-related topics are transportation planners and urban designer. The transportation planner group is interested in objective assessment of the built environment and its association to higher rates of walking trips for transportation [8]. The urban designers on the other hand, are more interested in the subjective assessment of built environment attributes and its influence on walking [9]. For the conduct of common beneficial research those two groups could easily come together to test the effect of the walking environment on walking travel behavior. Therefore, this paper presents comprehensive approaches for assessing walkability.

\section{METHODOLOGY}

In the year 2002, USA has developed a NEWS. NEWS does the subjective assessment of occupants' perception regarding their neighborhood's built environment attributes influencing walkability, the main items in this questionnaire are residential density, diversity in terms of land use mix, street connectedness, infrastructure for walking, neighbourhood aesthetics, traffic hazard and crime. NEWS has been validated in several countries.Moderate to high test-retest reliabilities have been found (most of the items $\geq 0.75$ ); thus an evidence was recorded for reliability of collected data from the occupants residing in potentially higher walkable neighbourhoods that gave higher ratings to residential density, diversity and street connectedness compare to low-walkable neighbourhoods occupants [10]. Studies done earlier, were only focusing on the subjective assessment of built environment attributes like density, land use mix and street connectedness though, these attributes had not been assessed objectively.

Three neighbourhoods in Putrajaya, Malaysia that differ on objective index based were selected as high, moderate and low walkable neighbourhood. The TIGER/Line shape files and database files from GIS data for streets, intersections, precinct boundaries and land use were analyzed to form:

(i) Gross residential density number of dwelling units per acre. The measurement forthe landuse mix was calculated based on the variability of development measured by seven variables these included, primarily use by the residence, secondly use by commercial activity, tertiarily use by government, quaternarily open spaces and garden or parks,quinarily amenities, senarily utility space for public, septenarily transportation) for all the selected neighbourhoods. The Simpson diversity index is used to quantify land use mix diversity.

(ii) Proximity index (Euclidean distance over Manhattan distance);

(iii) Link - node ratio (Number of edges divided by the number of vertices within a particular precinct). The Indices used for objective assessment of built environment attributes are given in Table 1. 


\section{$2.1 \quad$ Subjects}

A two-stage cluster sampling was done to select 402 children and adults aged between seven to sixty-five. All the respondents were government quarters resident of Putrajaya. For this research pool for the sample was selected from residential zones within three chosen neighborhoods, these were specifically classified on the basis of their respective walkability attributes into three strata: high walkable; moderate walkable and less walkable. Here neighborhood could be considered as a living in close proximity of 400 meters to 800 meters to all services based on the neighborhood unit model as this model has been used in the Putrajaya master plan [11]. Neighborhood walkability was determined using walkability index calculates with the help of GIS data and data available in master plan of Putrajaya related to four built environment attributes of 3 precincts selected for studies, those attributes include residential gross densities, diversity in terms of land use mix was calculated with the help of simpsonsdiversity index with values near to 1 consider as higher ratings of these attributes representing more walkable neighborhoods, accessibility to different facilities are calculated in Arc GIS 10.3 for that proximity analysis is carried out on a 400-800 meter-radius, street connectivity is calculated with the help of link-node ratio and is denoted by $\beta$ (beta) when the street network has greater connectivity b value is likely to rise too. Simple random sampling, were done to select a family unit from each precinct only one respondent per family unit was asked to fill the questionnaire. Persons who were not capable to walk without support, or not able to read English and respond were excluded. Respondent' socio-demographic characteristics are shown in Table 2.

\subsection{Procedures}

Sample of population was selected from low walkable Precinct 8, moderate walkable Precinct 9, and highly walkable Precinct 18. Selected neighbourhoods were considered as high, moderate and low walkable neighbourhood based on their walkability index. All the data on land use and each precinct specific data to be use for the indices were obtained from the Putrajaya [11] and

TABLE 1. INDICES USED FOR OBJECTIVE ASSESSMENT OF BUILT ENVIRONMENT ATTRIBUTES

\begin{tabular}{|c|c|}
\hline Built Environment Attributes & Indices \\
\hline Gross Residential Density & $\sigma=\frac{\mathrm{n}}{\mathrm{A}}$ \\
\hline Simpson's Diversity Index & $\mathrm{D}=1-\left(\frac{\sum \mathrm{n} "\left(n^{\prime \prime}-1\right)}{\mathrm{N}(\mathrm{N} \text { "- } 1)}\right)$ \\
\hline Proximity & Proximity Index $=\frac{\text { Euclidean Distance }}{\text { Manhattan Distance }}$ \\
\hline Street Connectivity & $\beta=\frac{\mathrm{e}}{\mathrm{v}}$ \\
\hline
\end{tabular}

Mehran University Research Journal of Engineering \& Technology, Volume 37, No. 3, July, 2018 [p-ISSN: 0254-7821, e-ISSN: 2413-7219] 
GIS Unit Perbadanan Putrajaya (Fig. 1). According to the data obtained it was found that Precinct 18 had higher residential density higher diversity of land use mix, higher distances to destinations and higher street connectivity. Whereas it was found from the data obtained from the report that Precinct 9 is medium dense, medium diversity in terms of its land use mixes, moderate distance to destinations but lower street connectivity, it was also found that Precinct 8 has a low residential density, low diversity in terms of its mix uses, low distance to destinations and low street connectivity.
High walkable Precinct 18 has a high gross residential density mainly due to residential type there were apartment of up to fifteen stories and high diversity in terms of land uses as these 12 storey apartments has different kinds of shops as discussed in the master plan of Putrajaya [11]. Street connectivity is also found higher in this precinct compare to the other 2 selected neighbourhood for studies. Therefore, it is found in this precinct that there are shorter distances to different facilities like school, mosque, food courts etc. Almost all or most of the facilities are required to be falling within four hundred meters by walk as this precinct is dominated

TABLE 2. RESIDENTS‘ DEMOGRAPHIC CHARACTERISTIC OF THE SAMPLE (N=402)

\begin{tabular}{|c|c|c|c|}
\hline \multicolumn{2}{|c|}{ Demographic Characteristic } & Frequency & Percentage $(\%)$ \\
\hline \multirow{2}{*}{ Gender } & Male & 183 & 46 \\
\hline & Female & 219 & 54 \\
\hline \multirow{3}{*}{ Marital Status } & Married & 271 & 67 \\
\hline & Single & 123 & 31 \\
\hline & Widowed & 8 & 2 \\
\hline \multirow{9}{*}{ Age (Year) } & $7-9$ & 44 & 11 \\
\hline & $10-12$ & 44 & 11 \\
\hline & $13-17$ & 44 & 11 \\
\hline & $18-22$ & 45 & 11 \\
\hline & $23-30$ & 48 & 13 \\
\hline & $31-40$ & 45 & 11 \\
\hline & $41-50$ & 44 & 11 \\
\hline & $51-60$ & 44 & 11 \\
\hline & $61-70$ & 44 & 11 \\
\hline \multirow{3}{*}{ Race } & Malay & 342 & 85 \\
\hline & Chinese & 40 & 10 \\
\hline & Indian & 20 & 5 \\
\hline \multirow{3}{*}{ Educational Attainment } & Primary or Less & 9 & 2 \\
\hline & Secondary & 90 & 22 \\
\hline & Tertiary & 303 & 75 \\
\hline \multirow{4}{*}{ Annual Household Income } & $\mathrm{RM}<2,500$ & 100 & 25 \\
\hline & RM 2,500 - RM 4,800 & 101 & 25 \\
\hline & $\mathrm{RM} 4,800$ - RM 8,400 & 101 & 25 \\
\hline & $>8,400$ & 100 & 25 \\
\hline
\end{tabular}

Mehran University Research Journal of Engineering \& Technology, Volume 37, No. 3, July, 2018 [p-ISSN: 0254-7821, e-ISSN: 2413-7219] 
by high-rise residential blocks and also multi-unit residential blocks of 4-6 stories are also found in this precinct in the form of terrace houses and low rise apartment. This precinct is characterized by diverse topography. Numerous public facilities are provided such as schools, schools for disable, mosque, market place, library and health care center[12-14].

Precinct 9 having a moderate walkability is located at walking distance to Putrajaya central a multimodal transportation terminal that is well integrated with other transport based on railway such as ERL (Express Rail Link) station and transportation based on road facilities such as bus terminal and a taxi center. Gross residential density is lower in this precinct as compared to high walkable Precinct 18. Precinct 9 has all the basic facilities such as school complex, parks and playgrounds, community police station within walking catchment of 400 meters. Precinct 9 comprises of a diverse mix of dwelling types such as terrace houses, condominium and apartments. Sidewalks are provided on all the streets in this precinct. Various public facilities are provided in this precinct like school complex, mosque, private office building, public market, health care center, post office, petrol station, community hall and a bus depot.

Precinct 8 has the lowest gross residential density of 5 units per acre and also less diverse in terms of land use mix compare to other 2 precinct 18 and precinct 9 . The dominant dwelling types found in Precinct 8 are detached luxury bungalows, semi-detached houses and terrace houses in an exclusive low-density residential environment. Schools are within walking catchment of 400 meters, so they prefer to walk to school. Many pocket parks are created in this precinct, but due to the low density environment, people only walk for leisure sometimes in the evening and mostly on weekends. Numerous public facilities are provided such as mosque, school complex, public library, community hall, supermarket, police station, information center, Putrajaya service center.

In each neighbourhood, 134 respondents were distributed an adapted version of the NEWS-A. The questionnaire is designed to assess perceptions of the residents regarding their neighbourhood built environment attributes like

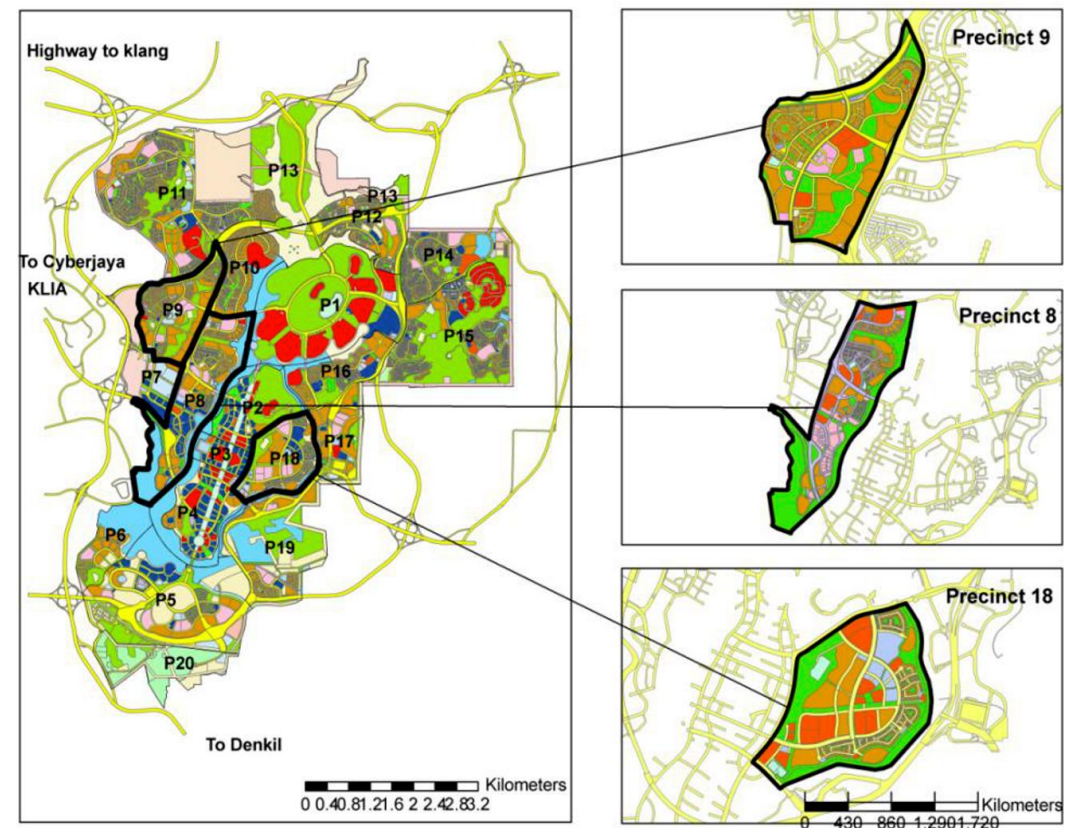

FIG. 1. STUDY AREAS (SOURCE: GIS UNIT PERBADANAN PUTRAJAYA) 
density of their residential area;diversity in terms of land use mix; street connectedness; walking infrastructure, i.e. foot paths; aesthetics; traffic hazard and crime. Except for residential densities and diversity in terms of the land use mix subscales were evaluated based on the 1-4 scale using a Likert scale (where, 1 refers to highly disagree, 2 refers to semi disagree, here 3 refers to semi- agree 4 refers to highly agree. Residential density items inquired about the types of dwellings, from detached single-family residents to more than 13-stories apartments or condominium, and the responses were ranging from 1 refers to none to 5 which refers to all. Residential density items were weighted relative to the average density of detached houses (e.g. Link houses were considered "12" times more dense in comparison with the detached houses. Apartment of up to 4 to 6 stories are rated to have " 25 " times more dense in comparison with the detached houses, on the other hand apartment of up to 7-12- levels were evaluated to be " 50 "times more dense in comparison with the detached apartments and lastly apartments of 13 levels and beyond are evaluated to be " 75 " times more dense in comparison with the detached houses) and conclusively all the weighted values were added to formulate a score consisting of density for residential subscale. These numbers $(12,25,50,75)$ are weighted for calculating the perceived residential density score what you get is a relative score reflecting (perceived) residential density, but not actual residential density. Whereas a diversity in terms of its land use mix was evaluated with the walking proximity from residences to different kind of facilities and business, the answers for the questionnaire varied from one to five minutes walking distance (coded as 1) whereas thirty minutes walking distance (coded as 4). If higher scores are obtained on diversity of mix uses that means business or other facilities are in close proximity [15].

\section{RESULTS AND DISCUSSION}

Data were coded, entered and analyzed using SPSSv20.0 to compare mean subscale scores between occupants of the three different neighbourhoods. Individual reliabilities alpha values were also checked for each item. Mean subscale score of high, middle and low walkable neighbourhood are given in Table 3 .

Table 3 shows amean scores's comparison on Neighbourhood Environment Walkability sub scales between occupants residing in high walkable Precinct 18; moderate walkable Precinct 9 and low walkable neighbourhood Precinct 8 . High walkable neighbourhood's residents in Precinct 18 in Putrajaya reported ratings indicative of higher residential density, diversity in terms of land use mix, access to services, street connectedness and walking infrastructure compare to occupants residing in moderate walkable Precinct 9 in Putrajaya and residents of low walkable residing in Precinct 8 in Putrajaya. Precinct 8 residents gave higher ratings to aesthetics in comparison to the moderate walkable residents and high walkable residents. For perceived traffic hazard and crime, the score did not differ much as Putrajaya is federal administrative center of Malaysia so there is a lot security there and the crime there is very low. All of the built environment attribute's value of $\alpha \geq 0.70$ shows that the NEWS-A is reliable tool for tropical countries. The theoretical value of alpha varies from any value less than or equal to 1 , including negative values, although only positive values make sense. Higher values of alpha are more desirable. Some professionals, as a rule of thumb, require a reliability of 0.70 or higher (obtained on a substantial sample) before they will use an instrument [16].

Findings indicate that substantial statistical differences were found in responses of residents' ratings of built environment attributes in objectively assessed high, moderate and low walkable areas for density, land-use mix, street connectedness and walking infrastructure reflecting that occupants from neighbourhoods with different built environment attributes do perceive these differences. 
TABLE 3. MEAN AND STANDARD DEVIATION SUBSCALE SCORES FOR DIFFERENT LEVEL OF WALKABILITY

\begin{tabular}{|c|c|c|c|c|}
\hline $\begin{array}{c}\text { Perceived Neighbourhood } \\
\text { Built Environment } \\
\text { Attributes (No. Items) }\end{array}$ & $\begin{array}{c}\text { High Walkable } \\
\text { (Precinct 18) (N=134), } \\
\text { Mean (SD) }\end{array}$ & $\begin{array}{c}\text { Moderate Walkable } \\
\text { (Precinct 9) (N=134), } \\
\text { Mean (SD) }\end{array}$ & $\begin{array}{c}\text { Low Walkable } \\
\text { (Precinct 8) (N=134), } \\
\text { Mean (SD) }\end{array}$ & $\begin{array}{c}\text { Reliability } \\
\text { (Alpha) }\end{array}$ \\
\hline Residential Density (6) & $282.90(.25)$ & $243.54(.21)$ & $2.13(.15)$ & 0.745 \\
\hline Land Use Mix (23) & $3.46(.50)$ & $2.44(.21)$ & $1.87(.26)$ & 0.942 \\
\hline Access to Services (3) & $3.25(.49)$ & $2.77(.42)$ & $2.61(.48)$ & 0.836 \\
\hline Street Connectedness (2) & $3.52(.34)$ & $2.24(.26)$ & $2.31(.34)$ & 0.872 \\
\hline Walking Infrastructure (3) & $3.36(.25)$ & $2.92(.57)$ & $2.96(.31)$ & 0.716 \\
\hline Aesthetics (4) & $2.82(.17)$ & $2.64(.23)$ & $2.14(.33)$ & 0.743 \\
\hline Traffic Hazard (3)* & $2.15(.37)$ & $2.15(.48)$ & $2.56(.29)$ & 0.789 \\
\hline Crime (3)* & $1.97(.49)$ & $2.54(.29)$ & & 0.738 \\
\hline \multicolumn{7}{|c|}{ Note: $*$ Higher Score Low Walkability } \\
\hline
\end{tabular}

\section{CONCLUSION}

Present findings suggest that perceived built environmental attributes were related to objectively assessed built environment attributes. Agreement between the objectively measured environment and perceptions of the environment was quite good for all three selected study sites so these both measures can be combined into a one model. The remaining built environment attributes like walking infrastructure and other subjective measures like aesthetics, traffic hazards and crime were not the basis of selection of particular Precinct.

Less walkable neighbourhood occupants gave higher ratings to aesthetics as compared to low walkable neighbourhood precinct 8 is likely to be more aesthetically pleasing than the other two precincts. Low walkable precinct 8 has a many interesting scenic view and is facing Putrajaya lake and mosque Besi which is the second principal mosque in Putrajaya after Putra Mosque. For this study socioeconomic factors and education level were not taken into account. The selected three precincts were selected to be comparable on census-based statistics for age- group and income-group.

\section{ACKNOWLEDGEMENT}

The authors would like to thank Mehran University of Engineering \& Technology, Jamshoro, Pakistan, for funding this research also Nazeer Hussain University, for facilitating this research and anonymous reviewers are also acknowledged for their diligent review and constructive comments.

\section{REFERENCES}

[1] Aditjandra, P.T., Mulley, C., and Nelson, J.D., "The Influence of Neighbourhood Design on Travel Behaviour:Empirical Evidence from North East England",Transport Policy, Volume 26, pp. 54-65, 2013.

[2] Sanches, S.P., and Ferreira, M.A.G., "Quantifying the Neighbourhood Environment Quality for Walking", 12th World Conference of Transportation Research, 2010 .

[3] Leslie, E., Saelens, B., Frank, L., Owen, N., Bauman, A., Coffee, N., and Hugo, G., "Residents' Perceptions of Walkability Attributes in Objectively Different Neighbourhoods: APilot Study", Health Place, Volume 11, No. 3, pp. 227-236, September, 2005.

Mehran University Research Journal of Engineering \& Technology, Volume 37, No. 3, July, 2018 [p-ISSN: 0254-7821, e-ISSN: 2413-7219] 
[4] Tal, G., and Handy, S., "Measuring Nonmotorized Accessibility and Connectivity in a Robust Pedestrian Network", Transportation Research RecordJournal, Transportation Research Board, Volume 2299, pp. 48-56, December, 2012.

[5] Norman, G.J., Nutter, S.K., Ryan, S., Sallis, J.F., Calfas, K.J., and Patrick, K., "Community Design and Access to Recreational Facilities as Correlates of Adolescent Physical Activity and Body-Mass Index", Journal of Physical Activity and Health, Volume 3, Supplement-1, pp. S118-S128, 2006.

[6] Nelson, M.C., Gordon-Larsen, P., Song, Y., and Popkin, B.M., "Built and Social Environments. Associations with Adolescent Overweight and Activity", American Journal of Preventive Medicine, Volume 31, No. 2, pp. 109-117, 2006.

[7] Koohsari, M.J., Badland, H., Sugiyama, T., Mavoa, S., Christian, H., and Giles-Corti, B., "Mismatch Between Perceived and Objectively Measured Land Use Mix and Street Connectivity: Associations with Neighborhood Walking", Journal of Urban Health, Volume 92, No. 2, pp. 242-52, April, 2015.

Saelens, B.E., Sallis, J.F., and Frank, L.D., "Environmental Correlates of Walking and Cycling: Findings from the Transportation, Urban Design, and Planning Literatures", Annals of Behavioral Medicine, Volume 25, No. 2, pp. 80-91, 2003.

[9] Moudon, A.V., Lee, C., Cheadle, A.D., Garvin, C., Johnson, D., Schmid, T.L., Weathers, R.D., and Lin, L., "Operational Definitions of Walkable Neighborhood: Theoretical and Empirical Insights", Journal of Physical Activity and Health, Volume 3, Supplement-1, pp. S99-S117, 2006.
[10] Cerin, E., Saelens, B.E., Sallis, J.F., and Frank, L.D., "Neighborhood Environment Walkability Scale: Validity and Development of a Short Form", Medicine \& Science in Sports \& Exercise, Volume 38, No. 9, pp. 1682-1691, 2006.

[11] Putrajaya, P., "Putrajaya Review of Master Plan", Malaysia, 1997.

[12] Qureshi, S., and Ho, C.S., "Towards Putrajaya Green City 2025 Implementing Neighbourhood Walkability in Putrajaya”, APSA Congress, pp. 409-420, University of Tokyo,Tokyo, Japan, 2011.

[13] Qureshi, S., and Siong, H.C.,"Redefining Walking Distance of Operational Planned Walkable Neighborhood in Malaysian Cities", AESOP 26th Annual Congress, pp. 11-15 Luglio, Ankara, July, 2012.

[14] Qureshi, S., “Assessing Built Environment Attributes of Walkable Neighbourhood in Malaysian Cities: The Study of Putrajaya”, Ph.D. Thesis, Universiti Teknologi Malaysia, Malaysia, 2017.

[15] Qureshi, S., and Ho, C.S., "From Digital Earth to Digital Neighbourhood: A Study of Subjective Measures of Walkability Attributes in Objectively Assessed Digital Neighbourhood", IOP Conference Series: Earth and Environmental Science, Volume 18, pp. 12160, 2014.

[16] Ritter, N.L., "Understanding a Widely Misunderstood Statistic: Cronbach's", Online Submission, 2010. 